\title{
Dopamine use is an indicator for the development of threshold retinopathy of prematurity
}

\author{
Michael B Mizoguchi, Thomas G Chu, Frederick M Murphy, Neil Willits, \\ Lawrence S Morse
}

\begin{abstract}
Aim-To assess whether treatment of premature infants with dopamine is a risk factor for development of retinopathy of prematurity (ROP).

Methods-A retrospective case series analysis of two groups was utilised with a minimum follow up of 6 months. Clinical profiles and patient risk factors were identified along with an evaluation of ROP progression and an analysis of clinical outcome. All infants were seen in a single community neonatal intensive care unit (NICU). 41 consecutive high risk infants were identified during a 36 month period whose birth weight was less than 1000 grams and who remained in the NICU without transfer until at least 28 days of age. Dilated indirect ophthalmoscopy fundus examinations were performed on all infants to identify the degree of and progression to threshold ROP.
\end{abstract}

Results-18 of 41 infants were treated with dopamine for hypotension. The group of infants requiring dopamine differed statistically from the non-dopamine treated group by having a slightly higher birth weight, a greater incidence of hypotension and colloid treatment, and in manifesting more advanced respiratory disease. Within the dopamine treated group, 12 of 18 infants (67\%) reached prethreshold ROP and seven infants $(39 \%)$ reached threshold ROP requiring laser treatment. In contrast, only three of the infants $(13 \%)$ who did not require dopamine for hypotension progressed to prethreshold $(p=0.001)$ and only one of these infants (4\%) progressed to threshold ROP ( $p=$ 0.02 ). Logistic regression analysis among other variables demonstrated that dopamine use and gestational age are important factors in this low birthweight population for predicting the development of threshold ROP (dopamine use: adjusted odds ratio $=119.88, p=0.0061$; gestational age: adjusted odds ratio $=0.061, p=$ 0.0043).

Conclusions-Dopamine use in low birthweight infants may therefore be a risk factor for the development of threshold ROP. More vigilant screening of high risk infants requiring dopamine therapy for systemic hypotension may be warranted. (Br F Ophthalmol 1999;83:425-428)

Retinopathy of prematurity (ROP) continues to be a significant cause of morbidity among very low birthweight infants. As survival rates of premature low birthweight babies have increased, so the frequency of ROP has risen. ${ }^{1-4}$ Initially, oxygen therapy was implicated in the aetiology of $\mathrm{ROP}^{5}$; however, it is now well recognised that ROP represents a multifactorial disease with numerous potential risk factors. ${ }^{6}$ Risk factors that have been reported include low birth weight, low gestational age, multiple gestation, prolonged parenteral nutrition, prolonged ventilator exposure, repeated blood transfusions, sepsis, apnoea, hypoxaemia, hypercarbia, and hypocarbia. ${ }^{6-10}$ The role of perinatal systemic complications and therapeutic interventions in the pathogenesis of ROP remains speculative. Systemic hypotension is a common complication of prematurity. Hypotension is often associated with other signs of low cardiac output, such as poor renal perfusion, decreased urine output and metabolic acidosis. It is usually initially treated with colloid, such as albumin, plasma, or other blood products. Dopamine, an $\alpha$ and $\beta$ adrenergic agonist, is often administered to affected infants to counteract hypotension when they are unresponsive to volume expansion. ${ }^{11}{ }^{12} \mathrm{We}$ have recognised, with this subpopulation of high risk dopamine treated infants, an increased risk for the development of threshold ROP.

\section{Methods}

We performed a retrospective chart review of infants born in the neonatal intensive care unit (NICU) of the Doctors Medical Center (DMC) during a 36 month period beginning January 1991. Infants selected for study included those with a birth weight of 1000 grams or less (very low birthweight infants) and who remained in the NICU without transfer until at least 28 days of age. Two groups of infants were studied: a treatment group receiving dopamine and a control group not requiring dopamine. The two groups were compared with respect to birth weight, severity of ROP, dopamine treatment, gestational age, hypotension, colloid treatment for hypotension, intraventricular haemorrhage, sepsis, patent ductus arteriosus, indomethacin treatment, hyaline membrane disease, oxygen requirement, duration of ventilation, Apgar scores at 1 and 5 minutes, bronchopulmonary dysplasia, and dexamethasone treatment. The gestational age was determined from the last menstrual period until birth and revised when appropriate after postnatal examination. Hypotension was defined as a mean arterial pressure less than $30 \mathrm{~mm} \mathrm{Hg}$. Patients with hypotension
Accepted for publication 30 September 1998 
Table 1 Clinical characteristics for infants with birth weight $\leqslant 1000 \mathrm{~g}$ *

\begin{tabular}{llll}
\hline Clinical characteristics & $\begin{array}{l}\text { Dopamine } \\
(n=18)\end{array}$ & $\begin{array}{l}\text { No dopamine } \\
(n=23)\end{array}$ & $\begin{array}{l}\text { Significancet } \\
(p \text { value })\end{array}$ \\
\hline Birth weight $(\mathrm{g})$ & $868(54)$ & $816(99)$ & $0.03 \mathrm{WA}$ \\
Gestational age (weeks) & $26.3(0.8)$ & $26.8(1.2)$ & $0.14 \mathrm{WA}$ \\
Hypotension & $18 / 18(100 \%)$ & $11 / 23(48 \%)$ & 0.001 \\
$\quad$ Colloid treatment & $18 / 18(100 \%)$ & $10 / 23(43 \%)$ & 0.0004 \\
Intraventricular haemorrhage & $9 / 18(50 \%)$ & $6 / 23(25 \%)$ & 0.21 \\
Sepsis & $1 / 18(6 \%)$ & $1 / 23(4 \%)$ & 1.00 \\
Patent ductus arteriosus (PDA) & $10 / 18(56 \%)$ & $9 / 23(39 \%)$ & 0.46 \\
$\quad$ Spontaneous closure of PDA & $0 / 18(0 \%)$ & $2 / 23(9 \%)$ & 0.58 \\
$\quad$ Indomethacin closure of PDA & $9 / 18(50 \%)$ & $7 / 23(30 \%)$ & 0.34 \\
$\quad$ Ligated PDA & $1 / 18(6 \%)$ & $0 / 23(0 \%)$ & 0.90 \\
Hyaline membrane disease & $17 / 18(94 \%)$ & $13 / 23(57 \%)$ & 0.02 \\
Oxygen requirement at day 2 (5) & $34(11)$ & $27(11)$ & $0.02 \mathrm{MW}$ \\
Days to first trial of extubation & $17.4(14.4)$ & $9.8(9.7)$ & $0.02 \mathrm{MW}$ \\
Apgar score at 1 minute & $5.8(2.3)$ & $5.3(2.9)$ & $0.60 \mathrm{p}(\mathrm{t})$ \\
Apgar score at 5 minutes & $7.5(1.5)$ & $7.5(2.4)$ & $0.94 \mathrm{p}(\mathrm{t})$ \\
Bronchopulmonary dysplasia & $14 / 18(78 \%)$ & $16 / 23(70 \%)$ & 0.82 \\
Dexamethasone treatment & $13 / 18(72 \%)$ & $15 / 23(65 \%)$ & 0.89 \\
\end{tabular}

* Values are mean (SD) for continuous data and number (\%) of infants for categorical data. + WA $=$ Welch-Aspin $t$ test; MW = Mann-Whitney comparison; $\mathrm{p}(\mathrm{t})=$ Student's $t$ test. $\chi^{2}$ test with Yates's correction were used for categorical data.

were treated with dopamine only after treatment with colloid failed to elevate the mean arterial pressure above $30 \mathrm{~mm} \mathrm{Hg}$. Dopamine infusion was initiated at $5 \mu \mathrm{g} / \mathrm{kg} / \mathrm{min}$ with subsequent rates not exceeding $20 \mu \mathrm{g} / \mathrm{kg} / \mathrm{min}$. In all cases, dopamine treatment was successful in elevating mean arterial blood pressure above $30 \mathrm{~mm} \mathrm{Hg}$. Clinical diagnosis of intraventricular haemorrhage was established by cranial ultrasonography. Sepsis was diagnosed by positive blood cultures at birth. Patent ductus arteriosus was confirmed by echocardiogram. Hyaline membrane disease was defined by an oxygen requirement greater than $30 \%$ at 48 hours and corroborated by chest $x$ ray. Oxygen requirements were defined by the fraction of inspired oxygen at 48 hours. Duration of ventilation indicates the number of days of mechanical ventilation until the first trial of extubation. Bronchopulmonary dysplasia was defined by chest $x$ ray criteria and oxygen requirement at 28 days. Dexamethasone treatment ranged from 1 to 6 weeks in duration.

Initial retinal examinations were performed between 4 and 8 weeks of age (mean 6 weeks). Each eye was graded using the standard international classification of ROP. ${ }^{13}$ Threshold ROP disease was also as defined in the Multicenter Trials of Cryotherapy for Retinopathy of Prematurity (CRYO-ROP). ${ }^{14-16}$ Infants with acute ROP were examined at 1-2 week intervals based upon the severity and progression of disease.

$\chi^{2}$ with Yates's correction was used for categorical data. For contiguous data three

Table 2 Dopamine use and ROP classification for infants $\leqslant 1000 \mathrm{~g}$

\begin{tabular}{|c|c|c|c|}
\hline Clinical characteristics & $\begin{array}{l}\text { Dopamine } \\
(n=18)\end{array}$ & $\begin{array}{l}\text { No dopamine } \\
(n=23)\end{array}$ & $\begin{array}{l}\text { Significance } \\
\text { ( } p \text { value })\end{array}$ \\
\hline \multicolumn{4}{|l|}{ Infant ROP stage: } \\
\hline No ROP & $1(6 \%)$ & $4(17 \%)$ & 0.50 \\
\hline Any ROP & $17(94 \%$ & $21(91 \%)$ & 1.00 \\
\hline Prethreshold ROP & $12(67 \%)$ & $3(13 \%)$ & 0.001 \\
\hline Plus disease & $9(50 \%)$ & $2(9 \%)$ & 0.009 \\
\hline Threshold ROP & $7(39 \%)$ & $1(4 \%)$ & 0.02 \\
\hline \multicolumn{4}{|c|}{ Anatomical zone on initial eye examination: } \\
\hline Zone I & $2(11 \%)$ & $3(13 \%)$ & 1.00 \\
\hline Zone II & $14(78 \%)$ & $15(65 \%)$ & 0.60 \\
\hline Zone III & $1(6 \%)$ & $5(22 \%)$ & 0.31 \\
\hline
\end{tabular}

${ }^{\star} \mathrm{p}$ Values are based on $\chi^{2}$ analysis with Yates's correction. comparisons of analysis were performed and compared: a two tailed Student's $t$ test which assumed equal variances in the groups, a Welch-Aspin $t$ test that does not assume equal variances, and a non-parametric MannWhitney comparison. The choice of test reported in the tables is based on a test of equality of variances as well as whether the data for a given variable seemed to contain outliers. Logistic regression and stepwise logistic regression models were used to look at the joint impact of dopamine use, gestational age, birth weight, intraventricular haemorrhage, and oxygen requirement on the development of threshold ROP. These analyses were run using SAS PROC LOGISTIC (SAS Institute, Cary, NC, USA).

\section{Results}

Of 776 infants admitted to the DMC NICU from January 1991 to January 1993, 101 infants had a birth weight less than 1000 grams. Of these 101 infants, 25 died and another 23 neonates were transferred out of the NICU with 12 being transferred in before inclusion into this study, resulting in a total of 41 infants eligible for the study. The clinical data for those infants receiving dopamine (18 infants) and those not receiving dopamine (23 infants) are outlined in Table 1. Although there was a slight difference in age between the groups, infants in the non-dopamine treated group tended to be smaller than those later receiving dopamine treatment. This is probably due to the inclusion of infants with intrauterine growth retardation in the non-dopamine treated group. The data do, however, suggest that there are important differences between those infants ultimately requiring dopamine and those not. Important differences include hypotension, hyaline membrane disease, oxygen requirement at day 2 , and the days to first trial of extubation. This suggests that there was greater respiratory distress in those infants ultimately receiving dopamine. As predicted, those requiring dopamine were also more unresponsive to colloid treatment and had greater hypotension.

Data from the group requiring dopamine and the group not requiring dopamine were compared with respect to degree and severity of ROP (Table 2). Of the 18 infants within the dopamine treated group, 12 infants (67\%) reached prethreshold ROP and nine infants (50\%) developed plus disease. In total, seven infants (39\%) progressed to threshold ROP requiring treatment. By contrast, in the nondopamine treated group, only three infants $(13 \%)$ reached prethreshold ROP $(p=0.001)$, two infants $(9 \%)$ developed plus disease $(\mathrm{p}=$ 0.009 ), and only one infant progressed to threshold ROP ( $p=0.02)$. Table 3 demonstrates that infants who reached threshold ROP were significantly different from those which did not reach threshold ROP in that they had younger gestational age and had longer oxygen requirements, indicating more pulmonary disease.

A series of logistic regression models was used to look at the impact of dopamine use, 
Table 3 Clinical characteristics for infants with ROP*

\begin{tabular}{llll}
\hline Clinical characteristics & $\begin{array}{l}\text { Threshold ROP } \\
(n=8)\end{array}$ & $\begin{array}{l}\text { No threshold ROP } \\
(n=33)\end{array}$ & $\begin{array}{l}\text { Significancet } \\
\text { (p value) }\end{array}$ \\
\hline Hypotension & $8(100 \%)$ & $21(64 \%)$ & 0.11 \\
Colloid treatment & $8(100 \%)$ & $20(61 \%)$ & 0.08 \\
Hyaline membrane disease & $8(100 \%)$ & $22(67 \%)$ & 0.14 \\
Days to first trial of extubation & $25.1(12.3)$ & $10.2(10.8)$ & $0.013 \mathrm{MW}$ \\
Gestational age (weeks) & $25.8(0.8)$ & $26.8(1.2)$ & $0.006 \mathrm{p}(\mathrm{t})$ \\
\hline
\end{tabular}

*Values are mean (SD) for continuous data and number (\%) of infants for categorical data. $\dagger \mathrm{MW}=$ Mann-Whitney comparison; $\mathrm{p}(\mathrm{t})=$ two tailed Student's $t$ test. $\chi^{2}$ with Yates's correction was used for analysis of categorical data.

gestational age, birth weight, intraventricular haemorrhage, and oxygen requirement on the development of threshold ROP. When all of these factors were included in the model, dopamine use (adjusted odds ratio $=119.88$, $\mathrm{p}=0.0014)$ and gestational age (odds $=0.061$, $\mathrm{p}=0.0043$ ) were statistically significant, while the other three factors failed to be significant at the 0.05 level. The odds ratios indicate that dopamine use was positively associated with the development of threshold ROP. When a stepwise logistic regression was used, dopamine use (adjusted odds ratio $=30.70$, $\mathrm{p}=0.032$ ) and gestational age (odds $=0.089$, $\mathrm{p}=0.0013$ ) were still significant, while the other variables were not entered into the model.

The eight infants who developed threshold ROP all underwent indirect laser photocoagulation as previously described. ${ }^{17}{ }^{18}$ All eyes of the treated infants remained anatomically attached at 6 months and had favourable outcomes.

\section{Conclusion}

ROP continues to be a significant cause of morbidity among very low birthweight infants. Effective treatment of ROP depends on the early and accurate recognition of those infants at highest risk for the development of ROP.

Low birthweight infants must contend with significant challenges for survival in the early perinatal period. A frequent challenge is the maintenance of cardiac output and systemic blood pressure. Despite intensive study of neonatal hypotension and its pharmacological management, an association with ROP has not been previously identified. Batton and coworkers found no difference between infants treated with cryotherapy and non-treated infants with regard to the presence of hypotension. ${ }^{19}$ Their definition of hypotension was any systemic blood pressure which required either volume replacement or inotropic medications; however, the use of dopamine was not specifically mentioned in their study. Moreover, Biglan et al reported similar blood pressure measurements in both their ROP and control patients. ${ }^{20}$ Additionally, the CRYOROP study did not identify hypotension as a prognostic factor in the natural course of ROP. $^{38}$

We did, however, find a strong association between the development of threshold ROP characteristics and the use of dopamine therapy for hypotension in high risk infants with a birth weight of 1000 grams or less ( $p=$ 0.02 , Table 2). Interestingly, one previous study looked for an association between the use of dopamine therapy and the development of ROP. $^{21}$ This study defined acute ROP as stage 1 disease or greater and did not find any association with dopamine use and the propensity to develop ROP. Because they did not try to relate their findings to threshold ROP, it is difficult to compare their findings with ours. In our study, 29 of the 41 infants were hypotensive. Hypotension was successfully treated in all 29 patients, with 10 of 41 infants responding to colloid treatment alone, and 18 of 41 infants responding to colloid plus dopamine treatment. Eight of the 29 infants went on to develop threshold ROP. None of the 12 non-hypotensive infants developed threshold ROP. Therefore, a direct measurement of the contribution of hypotension alone to the risk of developing threshold ROP cannot be estimated from our data.

In comparing our dopamine treated and non-treated groups, the two populations were statistically identical regarding other known risk factors for ROP such as gestational age, ${ }^{3}$ intraventricular haemorrhage, ${ }^{10}$ bronchopulmonary dysplasia, ${ }^{10}$ and dexamethasone treatment $^{19}$ (Table 1). The degree of retinal maturation (Table 2) was also not significantly different in the dopamine treated infants when compared with the non-treated infants. Therefore, the degree of retinal maturation alone does not appear to have unfavourably predisposed the dopamine treated group to the development of threshold ROP.

To answer the question of what factors ultimately contributed to the greater likelihood of developing threshold ROP, we compared the clinical characteristics of those infants who developed threshold ROP with those infants who did not reach threshold ROP (Table 3). The data show that the two groups were different only with respect to the days to first trial of extubation and gestational age. This would suggest that there was greater respiratory distress among those who ultimately developed threshold ROP. Hypoxia has been associated with the development of ROP and those that developed ROP tend to be a more ill population of infants. Within the threshold ROP group, however, it is equally significant that $39 \%$ of the dopamine treated infants developed threshold ROP while only $4 \%$ of the non-dopamine treated group went on to develop advanced stages of ROP ( $p=0.013$, Table 2). A logistic regression analysis was performed to assess the impact of these and other variables and demonstrated that in this population of low birthweight infants, only dopamine use and gestational age are important factors for predicting the development of threshold ROP. When other potential predictors were assessed for threshold ROP, none was seen as significant. Lastly, even when we adjusted for the possible impact of those other variables, dopamine and gestational age are still seen as significant factors, with the estimates of the adjusted odds ratios coming out about the same in each of the models used.

Why dopamine use should predispose low birthweight infants to the development of 
threshold ROP remains unknown and speculative. Dopamine is a potent inotropic agent with significant $\alpha$ and $\beta$ adrenergic activity. Within the retina, $\alpha$ adrenergic receptors have been identified in retinal vasculature. ${ }^{22-24}$ Dopamine stimulation of these $\alpha$ adrenergic receptors could be postulated to result in retinal vasoconstriction. In infants receiving supplemental oxygen, dopamine use in the setting of neonatal hypotension may act synergistically with oxygen to further constrict retinal vasculature, resulting in an exacerbation of retinal ischaemia and the initiation of the development of ROP. Moreover, within the central nervous system, dopamine has been implicated in controlling the blood-brain barrier permeability. ${ }^{25}$ Likewise, dopamine may also have a role in modulating the blood-retina barrier and the release of vasoproliferative factors in ROP. Dopamine has also been shown to play a primary role in retinal neuromodulation. ${ }^{26}$ Dopamine metabolism within the retina has been correlated with eye growth and maturation. ${ }^{27-29}$ Administration of dopamine to premature infants may interfere with this normal maturation process and, therefore, may increase the risk of developing threshold ROP.

Our findings must be tempered somewhat by the realisation that dopamine use, itself may not be the sole factor responsible for the development of threshold disease, but rather may select for a sicker subpopulation of low birthweight infants at risk for the development of threshold ROP. Regardless of the underlying mechanism whereby dopamine may predispose low birthweight infants to the development of threshold ROP, dopamine use appears to have significant predictive value. Therefore, increased vigilance of screening in low birthweight dopamine treated infants appears warranted.

Presented in part at the Annual Meeting of the Association for Research in Vision and Ophthalmology, Sarasota, Florida, USA, 3 May 1993.

1 Gibson DL, Sheps SB, Schechter MT, et al. Retinopathy of prematurity: the new epidemic? Pediatrics 1989;83:486-92

2 Gibson DL, Sheps SB, Uh SH, et al. Retinopathy of prematurity-induced blindness: birth weight-specific survival and the new epidemic [see comments]. Pediatrics 1990;86:405-12.

3 Palmer EA, Flynn JT, Hardy RJ, et al. Incidence and early course of retinopathy of prematurity. The Cryotherapy for Retinopathy of Prematurity Cooperative Group. OphthalRetinopathy of Prematurity

mology $1991 ; 98: 1628-40$.
Valentine PH, Jackson JC, Kalina RE, et al. Increased survival of low birth weight infants: impact on the survival of low birth weight infants: impact on the
incidence of retinopathy of prematurity. Pediatrics $1989 ; 84$ : inciden $442-5$.
5 Kinsey VE. Retrolental fibroplasia: cooperative study of retrolental fibroplasia and the use of oxygen. Arch Ophthalmol 1956;56:481.

6 Ben Sira I, Nissenkorn I, Kremer I. Retinopathy of prematurity. Surv Ophthalmol 1988;33:1-16.

7 Gunn TR, Easdown J, Outerbridge EW, et al. Risk factors in retrolental fibroplasia. Pediatrics 1980;65:1096-100.

8 Schaffer DB, Palmer EA, Plotsky DF, et al. Prognostic factors in the natural course of retinopathy of prematurity. The Cryotherapy for Retinopathy of Prematurity Cooperative Group. Ophthalmology 1993;100:230-7.

9 Campbell PB, Bull MJ, Ellis FD, et al. Incidence of retinopathy in tertiary newborn intensive care unit. Arch Ophthalmol 1983;101:1686-8.

10 Brown DR, Biglan AW, Stretavsky MM. Retinopathy of prematurity: the relationship with intraventricular hemorrhage and bronchopulmonary dysplasia. 7 Pediatr Ophthalmol Strabismus 1990;27:268-71.

11 Padbury JF, Agata Y, Baylen BG, et al. Dopamine pharmacokinetics in critically ill newborn infants. 7 Pediatrics 1987;110:293-8.

12 Padbury JF, Agata Y, Baylen BG, et al. Pharmacokinetics of dopamine in critically ill newborn infants. $f$ Pediatrics 1990;117:472-6.

13 Committee for the Classification of Retinopathy of Prematurity. An international classification of retinopathy of prematurity. Arch Ophthalmol 1984;102:1130-4.

14 Multicenter Trial of Cryotherapy for Retinopathy of Prematurity. Preliminary results. Cryotherapy for Retinopathy of turity. Preliminary results. Cryotherapy for Retinopathy of 106:471-9.

15 Multicenter Trial of Cryotherapy for Retinopathy of Prematurity. One-year outcome-structure and function. Cryotherapy for Retinopathy of Prematurity Cooperative Group. Arch Opthalmol 1990;108:1408-16.

16 Multicenter Trial of Cryotherapy for Retinopathy of Prematurity. Three-month outcome. Cryotherapy for Retinopathy of Prematurity Cooperative Group. Arch Ophthalmol 1990;108:195-204.

17 Benner JD, Morse LS, Hay A, et al. A comparison of argon and diode photocoagulation combined with supplemental oxygen for the treatment of retinopathy of prematurity. Retina 1993;13:222-9.

18 Landers MB, Toth CA, Semple HC, et al. Treatment of retinopathy of prematurity with argon laser photocoagulation. Arch Ophthalmol 1992;110:44-7.

19 Batton DG, Roberts C, Trese M, et al. Severe retinopathy of prematurity and steroid exposure. Pediatrics 1992;90:5346 .

20 Biglan AW, Cheng KP, Brown DR. Update on retinopathy of prematurity. Int Ophthalmol Clin 1989;29:2-9.

21 Hammer ME, Mullen PW, Ferguson JG, et al. Logistic analysis of risk factors in acute retinopathy of prematurity. Am f Ophthalmol 1986;102:1-6.

22 Nielsen PJ, Nyborg NC. Adrenergic responses in isolated bovine retinal resistance arteries. Int Ophthalmol 1989;13: 103-7.

23 Ferrari-Dileo G, Davis EB, Anderson DR. Response of retinal vasculature to phenylephrine. Invest Ophthalmol Vis Sci 1990;31:1181-2.

24 Ferrari-Dileo G, Davis EB, Anderson DR. Effects of cholinergic and adrenergic agonists on adenylate cyclase activity of retinal microvascular pericytes in culture. Invest Ophthalmol Vis Sci 1992;33:42-47.

25 Palmer GC. Neurochemical coupled actions of transmitters in the microvasculature of the brain. Neurosci Biobehav Rev 986;10:79-101.

26 Dowling JE. Retinal neuromodulation: the role of dopamine. Vis Neurosci 1991;7:87-97.

27 Laties AM, Stone RA. Some visual and neurochemical correlates of refractive development. Vis Neurosci 1991;7:125-

28 Stone RA, Lin T, Laties AM, et al. Retinal dopamine and form-deprivation myopia. Proc Natl Acad Sci USA 1989;86: 704-6.

29 Stone RA, Lin T, Iuvone PM, et al. Postnatal control of ocular growth: dopaminergic mechanisms. Ciba Found Symp 1990;155:45-57. 